\title{
Caring Women with Dementia: An Unheard or Hidden Suffering
}

\author{
Ravinder Singh ${ }^{1}$, Upmesh K.Talwar ${ }^{2}$, Vibha Sharma ${ }^{3}$, V.K.S. Gautam ${ }^{4}$ \\ ${ }^{1}$ Department of Medical Anthropology, ${ }^{3}$ Clinical Psychology, ${ }^{4}$ Neurosurgery \\ Institute of Human Behaviour \& Allied Sciences, Dilshad garden, Delhi, India \\ ${ }^{2}$ Former Assistant Professor, Department of Social Work, CUHP, Dharmshala, H.P.
}

\begin{abstract}
Paper illuminates four case studies of women with dementia. Contents of the case studies reveal the unheard or hidden suffering of primary care givers in the family and their concerns. It focus on the problem of these women with dementia in the family, family and kinship care dynamics, who cares them in family and their challegenes of caring?
\end{abstract}

Keywords : Women, Dementia, Family \& Kinship care

\section{INTRODUCTION}

According to DSM-IV the dementia is a clinical syndrome of cognitive impairment, deterioration from a previous state and associated with functional decline ([1]. These cognitive impairments further includes the short term memory loss and at least one additional domain cognitive impairments such as apraxia, agnosia, aphasia, or loss of executive functioning, collectively fall under the rubric of dementia. It also includes degenerative dementia: Alzhiemer's disease, vascular dementia and frontotemporal dementia [2]. DSM-IV mentioned the behavioral description-delusion, with depression or with behavioral disturbance in first two subtype of dementia, whereas frontotemporal dementia does not have well defined explicit diagnostic criteria in DSM-IV. The clinical features frontotemporal dementia includes changes in behvaiour and personality [3]. One of the core criteria is presence of Lewy bodies, though not included in DSM-IV but will likely emerge as diagnostic category in DSM- $\mathrm{V}$, is presence of visual hallucination [2].

It causes social suffering to the family as well as to community. About 450 million people are affected in the world. One estimate reveals 13 percent of disability-adjusted life years (DALYs) are due to neuropsychiatric disorders [4]. Dementia /Alzheimer's disease (AD) is a deterioration of intellectual function and other cognitive skills interfering with social and other occupational functions. It is most common diseases worldwide among the people above 65 years. The prevalence of dementia becomes the double with every five year of increase in age [5-9]. The behavioral and other psychological symptoms of dementia are a major source of stress to family members caring their patients. It has been proved that training to family caregivers in behavioral management techniques, including problem solving, memory training, and reality orientation has reduce the level of agitation and anxiety in patients with dementia[10-11], counseling interventions for caregivers have shown positive results in such cases[12]. Medical anthropologists have produced remarkable work on dementia/Alzheimer's Disease in different national sites of Brazil, Canada, Germany, India, Japan, Netherlands and the United States around the world[13-14,a,b] . It includes dementia-near-death and Life itself [15], physician and family perspective on "troublesome" behavior of people with dementia [2], diagnosing dementia [16]; genetic susceptibility and Alzheimer's disease [17]; and social, cultural and ethical issues relating to patients with dementia [18]. Lawrence Cohn's No Aging in India: Alzhemier's, the Bad Family, and Other Modern Things, is the pioneer anthropological work on dementia in India [14a]. There are ethical and legal issues examined relating to patients with dementia and epilepsy in the Indian perspective [19].

Normally caring is considered to be the work of the women followed by other kinsmen in the family. But what happened when these women are lost in themselves? Then who care them most? Can the family and kinship caring intervention be analyzed in home or in community or in hospital situation? Anthropology of caring has already explored a new path for individuality, alterity, gender relations, and new form of sociality in everyday life experiences of caregivers, spouses, children, and other relatives who provides day to day care to person with illnesses living in the home [20]. Anthropologists have reformulated the kinship as the study of form of caring and being cared for [21]. The family and kinship care is the complementary part of comprehensive patient care in the families of patients with dementia and epilepsy [22]. In this paper we are illuminating the four women with dementia; their family based kinship care dynamics, their importance and issues relating to primary care giver within the family situations. 


\section{Material and Methods}

The interviews of twelve care givers $(\mathrm{N}=12)$ of women with dementia with their consent, were held in OPD as well as in wards of the hospital between August 2006 and July 2007. Someone from the family members or other kinsmen always accompanied the women with dementia and was interviewed as a care giver. They were from the different places in Delhi: Sundar nagari, Gokul puri, Pandav nagar, Dilshad garden, Krishna nagar, Nehru Nagar, Shahdara, New Govindpura, all comprised as Trans Yamuna of Delhi. Most of patients visit this tertiary neuropsychiatric hospital. A semi structured schedule was divided into four major sections: first, deals with the socio-demographic detail; second, food habits- how many times patients in the past has been taking the meal per day, constituents of the staple diet-green vegetables, fruits consumption, spices consummation, Non/ vegetarian. Third, family profile, family supporting members, time spent in caring and the fourth, life history of the person: scholastic performance, nature of job and earning, number of hours spent in the jobs, level of satisfaction and stress of the job. Life after the retirement, marital history, family responsibilities, peer group activities in the life and important events in the life. This information was collected in a structured schedule. One of the authors (RS) conducted an unstructured interview with care giver. Here while writing this paper we have restricted our focus to the family and kinship care composition and the caring modalities in the care of women with dementia. Other detail neither analyzed nor utilized as it was useful for the clinical and neurological interpretation.

\section{Women with Dementia}

We are giving the four brief case histories of women with dementia- four women. Most of the details, such as diet, routine of patient in the past years, brain activities of calculation, teaching etc. help to Neurologist in clinical assessment of these patients and deliberately have not used. We have only focused the family and kinship care of women with dementia (pseudo name).

1. HKD, 60 years Hindu jat woman, came from the rural village Rehman Pur of Shamali, Bulandshar, UP. She is illiterate housewife and look after the agriculture activities in the house as well as in the field in past. She had been working 12 to 17 hours every day. She had seven children, four boys and three girls. All are married and well settled. Married sons have settled away from their ancestral village. Both, husband and wife, HKD, stay back alone and their monthly income is about 10,000/-pm. She had been diagnosed a case of $\mathrm{AD}$ at the age of 60 years. She is well build and tall. A brief history about her life style in past shows that she is married for 45 years where in she took all the responsibility of the household activity. Her husband told about her she never felt more stress. She spent 3 to 4 hrs in recreational work with her peer group. Her husband claims that she is satisfied. Nothing has disturbed her in her family.

In the Family and its support, all married sons stay away from the parents, particularly from the patient mother, her husband visiting their married sons and daughter. Wife, HKD, patient remains back in her house alone . Often sons contribute economically to the parents. But physically they hardly stay long. It is apparent parents living alone in the village setting. Most of the time husband cares his wife; none of the daughters-in-law stay together though their children often stay back with grandmother. Financially sons support the parental family. Married life of the patients, HKD, is very satisfactory and supportive to each other in their life for 45 years. As the mother, HKD cared well her children, home and enjoyed happy married life in company of husband.

2. KR is another woman, above 60 years, diagnosed with Dementia. She had been complaining the memory loss, failing to recognize the sibs and kins in the family during the early November and December 2006. Her family members treated her with local trained doctors in Baraut. But there was no cure till Jan. 2007. Meanwhile she rapidly lost the memory and referred here where she was diagnosed as dementia of $\mathrm{AD}$ type. Her daughter brought her in Delhi for treatment. This daughter further adds that KR has four children and a husband. One sister and son are already married. Married son had been living together till October, 2006, just before these symptoms of memory loss appeared in KR. KR used to love her married elder son Ashok and his children and till then KR was very active in the home chore activities of the house. As the patient began to exhibits the symptoms as mentioned earlier, she now requires more time for her care and sympathy of other family members. During this time, elder married son, refused to take care of her mother and his wife also refused to look after her mother-in-law. Her husband also refused to care her in such a situation and even did not help for her treatment as the wife. Then her unmarried two sons in the state of dilemma transferred her to their elder sister's house in Delhi for care and treatment. Both unmarried sons are looking after the economic expenditures of patients- their mother. In sum, married daughter is looking after her AD mother belongs to the high socio economic stratum of a rural village where a married daughter ideally does not keep her parents in her in-laws house. Two unmarried sons supporting the economic needs, but still seek the other social support from their married sister.

3. SK, 71 years old Hindu woman, housewife, had three children - one son and two married and one married son is living on the top floor of the three story house. SK and her husband live on the ground floor. Her only married son has two children living separately on top of the house. Her husband adds further that he runs his family life on the 
pension of Rs 3000/-pm and his son hardly supports them, in contrast they support as their son's family. Their son does not earn much.

4. AD, 75 years, old Hindu illiterate woman has five married children and the husband who look after her for the four years. Four years ago she developed the dementia and lost to no work. AD remains the part of family and being cared by the well settled married five sons and a daughter. Her daughters- in- law and their children care much. She had been a active housewife an used to work 8 to 10 hrs. She takes the different smoking means, traditional hukka, chilim, tobacco and bidi. She does not earn herself. As far as her part on the responsibility of bring up children which did nicely and had their own house, settled well all children and still pay attention to the social responsibility. Occasionally she spends times with her pear group. As her younger son tells that she thinks much of the past unpleasant incidences.

\section{Women with Dementia}

\section{Women with Dementia: Do the Husbands Care?}

The detail of family, sibs and other possible care givers in the family and kinship system, it seems from these brief, wherein we have restricted use of the family detail. They have possible resources are available for care and treatment of dementia and epilepsy. In case of dementia the clinical symptoms appear when a person cross the age of 50 year or above, in our analysis the average age is 63.5 years, here at this age nobody is around the grand old person as patient, man or woman, with dementia expect the spouse-husband or wife. The children by this time get married off and stay away or separated from their parents. The poor persons with dementia remain behind and don't know with whom she or he is living with. They, as caring affinal kin knows well what he or she is to us but the person with dementia is now in a different personhood in the family. In our analysis we observed that among patients with dementia remains with their spouse - either husband or wife. Only unmarried children, daughters or sons remain to support in the family. Most of the children married, particularly son and their wife either prefer to stay away from the parental house or even staying together then they remains functionally away from the care giving mechanism though structurally together with their families. Wives and the children are living in the different space within the same parental house. Such are the sons who are forced to stay with as they cannot go outside to live.

Like in case of HKD have seven married children, four sons and three daughters. Daughters are away and outside the kinship care network as they remain with the in laws. Her sons hardly find time for the care their mother and whole responsibility remains with father, who is entirely for her care besides other home chore. In contrast, KR, another woman from the rural area of Baruat near Delhi and her husband refused to care her. She also denied care by her elder married son separated from the parental family and starts living separately with his wife and children and do not care to his demented mother. Remaining unmarried sons, under the stress of care, approach the elder married sister in Delhi for help in her treatment, as dutiful daughter she took all responsibility for her mother treatment. However the unmarried younger brothers economically support her elder sisters in her treatment. Married daughter and her husband are taking care of KR- here, it reminds us about a film "complaints of a dutiful daughter" by Deborah Hoffman and the Taylor's article "on recognition, caring and Dementia" and the Politics of care, a commentary of Lawrence Cohen on the latter article. In this film a tag appears "What's, a daughter to do when her mother ask: "how exactly are we related?" [23].

In contrast, $\mathrm{AD}$, a woman of 75 years being treated for dementia, who is cared well not only by her sons but by their wives too and her grand children also care the grandmother. The care of elderly person with dementia pose a different stress to the care givers- usually the spouse either husband or wife- least supported by the eldest married sons, however younger unmarried sons always extend their help. Whereas in case of SK the husband care his wife, neither son nor his wife share this responsibility of care the mother-in-law in the family.

Hargave reported similar observations about the family and kinship caring ties of among AfricanAmerican caregivers to the person with dementia. She emphasized on the features of family and kinship in African-American caregivers for dementia patients mentioned that the nature of the relationship between the dependent elder and his/her caregiver vary across ethnic group. White caregivers are mostly are the spouses, whereas African-American caregivers are more likely to be adult children, extended relatives, or friends [24]. Several studies emphasizing the care giving aspects among the African-American are well reported in caring the people with dementia among black and white people-a comparison of adaption, adjustment, and service utilization for the Care of dementia in Black and white caregivers[25], different issues of race, ethnicity, and culture in care giving research[26], dynamics of care giving of demented elder among black and white families[27] and an analytical review of racial, ethnic, and cultural differences in dementia care givers[28]. 
In general, African-American caregivers as compared to white caregivers are more likely to be younger, unmarried, with less formal education, and fewer financial resources. Because of their lower income and higher poverty rates, the financial stress of care giving may pose a greater emotional burden on AfricanAmerican caregivers [24]. Hargave mentioned African-American caregivers, as compared to white caregivers, are more likely to provide more hours of care, higher-intensity care, and are more likely to report more unmet needs in terms of support and access to services [24]. Many African -American caregivers are also actively caring for other people in addition to the frail elderly, such as minor children, grandchildren, and other family members. Even though African-American caregivers are caring for severely debilitated elders and other family members, they are less likely than white caregivers to use formal care services like nursing homes [29].

Studies have reported that African-American family care giving of dependent elderly persons is performed within a collectivistic structure composed of different people with varying levels of involvement in daily care giving activities [30-31]. Since kinship ties are a very powerful force in African-American families, many investigators thought that African -American caregivers receive significant support from their network of family members. However, more recent studies suggest that prior research may have overestimated the availability and extent of support that African-American caregivers receive from other family members [25; 3233]. These studies suggest that adult children of dependent elderly persons may be adversely affected by the other commitments in their own lives, which may severely limit the amount of assistance they can offer frail African-American elderly. In the midst of an extended family network, one primary caregiver emerges who bears the burden of being the sole decision maker, and has few opportunities for shared responsibility and shared decision making [33].

\section{CONCLUSION}

The behavioral and psychological symptoms of dementia are major causes of stress to family and kinsmen providing care to women with dementia. Above interpretation from these family and kinship care analysis, we are to think, that does family and kinship caring still central of such women? While examining the about these case studies where women are the patients then who care them? The caring in the dementia, old people suffer, in most of cases, only the spouse cares- either husband or wife. Since the family and kinship care, as seems, is still central of caring such women the training, sensitization or orientation programme should be designed for family and kinship caregivers in the management of these women, including problem solving, memory training, and reality orientation. These can reduce the level of agitation and anxiety in women with dementia. The challenge for developing countries like India is to develop culturally appropriate interventions that can be delivered, within existing resources, as support to the role as caregivers in their families [22].

We feel about a care giving model for the north Indian population groups which should be home based care coupled with regular training about the modalities of caring must be given to the family and kinship members of the women with dementia [22]. Their care giver should be provided material and other relevant information about such diseases. In many developing countries, people with dementia are still thinking it as the madness and consult the traditional healers and such consultations are more common in patients with epilepsy and hysteria. A simple model for the management of dementia, epilepsy and other neurological disorders must be based on existing community-based health care resource providers, trained to provide such services which may reduce burden of caregivers in the family of such diseases.

\section{Acknowledgement}

We are thankful Dr Meena Gupta, former Director, IHBAS and Professor of Neurology in GB Pant hospital Delhi for her encouragement.

\section{REFERENCES}

[1] American Psychiatric Association (1994). Diagnostic and Statistical Manual of Mental Disorders (DSM IV). Washington D C :American Psychiatric Association.

[2] Hinton, Ladson, Yvette Flores, Carol Franz, Isabel Hernadez and Linda S Mitteeness. (2006). The Borderlands of primary Care: Physician and Family Perspective on "Troublesome" Behavior of People with Dementia, Chapter-2 in Thinking about DementiaCulture, Loss, and the Anthropology of Senility, ed. Annette Leibing and Lawrence Cohn (2006). Rutgers Universe Press, New Jersey

[3] Miller, Bruce and Andrew Gustavson(2000). “Alzhiemer's Diseases and Frototemporal Dementia” in Textbook of Geriatric Neuropsychiatric ed. C E Coeffy and J I. Cummings. Washington D C :American Psychiatric Press.

[4] Chandra,V., R. Pandav, R. Laxminarayan,C.Tanner, B.Manyam, S. Rajkumar, D. Silberberg, C. Brayne, J.Chow, .Herman,F. Hourihan, S. Kasner, L. Morillo, A. Ogunniyi, W.Theodore, and Z. Zhang( 2006). Neurological Disorders. Chapter-32 in Mental health Disorders. The International Bank for Reconstruction and Development / The World Bank, 2006

[5] Henderson, A. S., and A. F. Jorm. 2000. "Definition of Epidemiology of Dementia: A Review." In Dementia, ed. M. Mario and N. Sartorius, 1-34.West Sussex, U.K.: John Wiley. 
[6] Chandra, V., M. Ganguli, R. Pandav, J. Johnston, S. Belle, and S. T.DeKosky(1998). "Prevalence of Alzheimer's Disease and Other Dementias in Rural India: The Indo-U.S. Study." Neurology 51 (4): 1000-8.

[7] Hendrie, H. C., B.O. Osuntokun, K. S.Hall,A.O.Ogunniyi, S. L.Hui, F.W. Unverzagt. 1995. "Prevalence of Alzheimer's disease and Dementia in Two Communities: Nigerian Africans and African Americans.” American Journal of Psychiatry 152 (10): $1485-92$.

[8] Rajkumar, S., S. Kumar, and R. Thara. 1997. "Prevalence of Dementia in a Rural Setting: A Report from India." International Journal of Geriatric Psychiatry 12 (7): 702-27

[9] Jorm, A. F., and D. Jolley. 1998. “The Incidence of Dementia: A Meta- Analysis.” Neurology 51 (3): 728-33.

[10] Brodaty, H., and M. Gresham(1989). "Effect of a Training Programme to Reduce Stress in Cares of Patients with Dementia." British Medical Journal 299 (6712): 1375-79.

[11] Haupt, M., A. Karger, and M. Janner. 2000. "Improvement of Agitation and Anxiety in Demented Patients after Psychoeducative Group Intervention with Their Caregivers." International Journal of Geriatric Psychiatry 15 (12): 1125-29.

[12] Marriott, A., C. Donaldson, N. Tarrier, and A. Burns. 2000. "Effectiveness of Cognitive-Behavioural Family Intervention in Reducing the Burden of Care in Carers of Patients with Alzheimer's Disease.” British Journal of Psychiatry 176 (1): $557-62$.

[13] Leibing, Annette and Lawrence Cohn (2006). Thinking about Dementia- Culture, Loss, and the Anthropology of Senility, ed. Rutgers Universe Press, New Jersey.

[14] Cohen, Lawrence (1994). “Old Age: Cultural and Critical Perspectives”. Annual Review of Anthropology 23:137- 158

[14a] Cohen, Lawrence (1998). No Aging in India: Alzhiemer's, the Bad Family, and Other Modern Things. Berkeley University of California Press.

[14b] Cohen, Lawrence (2003). "Is Treating Dementia Ironic?" in Illness and Irony: On the Ambiguity of suffering in Culture, ed. Michael Lambek and Paul Anzte. New York: Berghahn.

[15] Kaufman, Sharon R.(2006). Dementia-Near-Death and "Life Itself", Chapter-1 in Thinking about Dementia- Culture, Loss, and the Anthropology of Senility ed. Annette Leibing and Lawrence Cohn (2006). Rutgers Universe Press, New Jersey

[16] Graham, Janice E (2006). Diagnosing Dementia: Epidemiological and Clinical Data as cultural Text, Chapter-4 in Thinking about Dementia- Culture, Loss, and the Anthropology of Senility Ed. by Annette Leibing and Lawrence Cohn (2006). Rutgers Universe Press, New Jersey

[17] Lock, Margaret, Stephane Llyod and Janalyn Prest (2006). Genetic Susceptibility and Alzheimer's Diseases. Chapter-6 in Thinking about Dementia- Culture, Loss, and the Anthropology of Senility ed. Annette Leibing and Lawrence Cohn (2006). Rutgers Universe Press, New Jersey

[18] Singh, Ravinder, Sarabjeet Khurana, Kiran Bala and Mahesh Bhargava (2011). Social, Cultural and Ethical Issues in Dementia, Chapter-24; in Clinical Neuropsychology Assessment and Rehabilitation : A Practical Approach, ed. Vibha Sharma and Shazadi Malhotra. Published by Harprasad Institute of Behavioral Sciences, Agra, UP.

[19] Sharma, Vibha; Ravinder Singh, Upmesh K Talwar and Mahesh Bhargava (2011). Ethical and Legal Issues related to Dementia and Epilepsy, Chapter-25 in Clinical Neuropsychology Assessment and Rehabilitation: A Practical Approach, ed. Vibha Sharma and Shazadi Malhotra. Published by Harprasad Institute of Behavioral Sciences, Agra, UP.

[20] Saillant, Francine and Serge Genset (2007). Medical Anthropology-Regional perspective and shared Concerned, ed. Blackwell Publishing, USA

[21] Borneman, John(1997). "Caring and Being Cared for: Displacing the Marriage, Kinship, Gender and Sexuality." International Social Sciences Journal, 154:573-584

[22] Singh, Ravinder; Vibha Sharma and Upmesh Kumar Talwar (2013). Patients with Epilepsy and Dementia: Does Family and Kinship Care Matter? Advances in Anthropology, 2013(in press)

[23] Cohen, Lawrence (2008). Politics of care: commentary on Janelle S Taylor's "On Recognition Caring, and Dementia". Medical Anthropology Quarterly, Vol.22 Issues 4 pp. 336-339

[24] Hargrave, Rita (2006) Caregivers of African-American Elderly with Dementia: A Review and Analysis. Annals of Long- Term care Vol: 14 Oct. 2006

[25] Hinrichsen GA, Ramirez M(1992). Black and white caregivers: A comparison of their adaption, adjustment, and service utilization. Gerontologist 1992; 32:279-381.

[26] Dilworth-Anderson P, Williams IC, Gibson BE. Issues of race, ethnicity, and culture in care giving research: A 20-year review (1980-2000). Gerontologist 2002;42(2):237- 272.

[27] Lawton MP, Rajagopal D, Brody E, Kleban MH(1992) The dynamics of caregiving for a demented elder among black and white families. J Gerontol 1992; 42:S156-S164

[28] Connell CM, and Gibson GD(1997). Racial, ethnic, and cultural differences in dementia care giving: Review and analysis. Gerontologist, 1997;37:355-364.

[29] Haley WE, Roth DL, Coleton MI, et al(1996). Appraisal, coping, and social supportas mediators of well-being in black and white family caregivers of patients with Alzheimer's disease. J Consult Clin Psychol 1996; 64:121-129.

[30] Dilworth-Anderson P, Williams SW, Cooper T(1999). Family care giving to elderly African Americans: Caregiver types and structures. J Gerontol B Psychol Sci Soc Sci 1999;54(4): S237-S241

[31] Burton LM, Dilworth-Anderson P(1999) The intergenerational family roles of aged black Americans. Marriage and Family Review, $1991 ; 16: 311-322$.

[32] Cox C, Monk A.(1996). Strain among caregivers: Comparing the experiences of African American and Hispanic caregivers of Alzheimer's relatives. Int. J. Aging Hum. Dev. 1996; 43:93-105.

[33] Fox K, Hinton W, Levkoff S(1999). Take up the caregiver's burden: Stories of the care for urban African American elders with dementia. Culture, Medicine, Psychiatry, 1999; 23:501-529. 